\title{
Hydrogen Safety Training for Researchers
}

S. Aceves, G. Petitpas, T. Ross and V. Switzer

\section{August 3, 2010}


This document was prepared as an account of work sponsored by an agency of the United States government. Neither the United States government nor Lawrence Livermore National Security, LLC, nor any of their employees makes any warranty, expressed or implied, or assumes any legal liability or responsibility for the accuracy, completeness, or usefulness of any information, apparatus, product, or process disclosed, or represents that its use would not infringe privately owned rights. Reference herein to any specific commercial product, process, or service by trade name, trademark, manufacturer, or otherwise does not necessarily constitute or imply its endorsement, recommendation, or favoring by the United States government or Lawrence Livermore National Security, LLC. The views and opinions of authors expressed herein do not necessarily state or reflect those of the United States government or Lawrence Livermore National Security, LLC, and shall not be used for advertising or product endorsement purposes.

This work performed under the auspices of the U.S. Department of Energy by Lawrence Livermore National Laboratory under Contract DE-AC52-07NA27344. 


\section{Hydrogen Safety Training for Researchers}

Salvador M. Aceves, Guillaume Petitpas, Timothy O. Ross, Vernon Switzer

Lawrence Livermore National Laboratory

7000 East Avenue, L-792

Livermore CA 94550

Phone: (925) 422 0864; Fax: (925) 4234250

E-mail: saceves@,llnl.gov

DOE Technology Development Manager: Antonio Ruiz

Phone: (202) 586-0729; Fax: (202) 586-9811

E-mail: Antonio.Ruiz@ee.doe.gov

Project Start Date: October 2008

Project End Date: September 2012

\section{Objectives}

- Prepare safety training materials for researchers unfamiliar with hydrogen technology

- Prepare advanced safety training materials for personnel in charge of hydrogen systems

\section{Technical Barriers}

This project addresses the following technical barriers from the Hydrogen Safety section (3.8) of the Hydrogen, Fuel Cells and Infrastructure Technologies Program Multi-Year Research, Development and Demonstration Plan:

H. Lack of Hydrogen Knowledge by Authorities Having Jurisdiction

I. Lack of Hydrogen Training Facilities

\section{Contribution to Achievement of DOE Hydrogen Safety Milestones}

This project will contribute to achievement of the following DOE milestones from the Hydrogen Safety section of the Hydrogen, Fuel Cells and Infrastructure Technologies Program Multi-Year Research, Development and Demonstration Plan:

- Milestone 17: Identify user needs for basic safety information

\section{Accomplishments}

- Completed a preliminary version of the web-based "Hydrogen Safety Class for Researchers"

- Conducted two rounds of peer review with distinguished hydrogen safety experts

- Delivered a final version of the web-based class that incorporated reviewers' comments

- Started working toward a hands-on safety class for technical personnel

\section{Introduction}

LLNL has been conducting hydrogen research for more than 50 years, starting with national security applications and continuing with hydrogen energy research. For many of these years, LLNL was designated as the pressure safety training facility for the whole DOE complex and other government institutions such as NASA. Many technicians 
and researchers visited LLNL to receive appropriate training on many aspects of pressure safety, including hydrogen technology, cryogenics, leak detection, and vacuum technology.

The national security hydrogen and high-pressure research conducted at LLNL demanded unique testing facilities, and these were built with funding from DOE Defense Programs. These facilities include a high pressure laboratory equipped with 4 hydrogencompatible test cells, each rated for $80,000 \mathrm{psi}$, and 4 pounds of TNT equivalent stored energy. LLNL also has a high explosive test facility (Site 300) for high-energy experiments with many pounds of TNT equivalent and many kilograms of hydrogen. Experiments in Site 300 are typically conducted in outdoor firing tables and monitored from the safety of a bunker. The remote location of this facility protects employees and property from any hazard.

These unique facilities and the expertise necessary to operate them are now being made available for hydrogen energy research through the development of training materials that may contribute to safe operation within the many institutions working for the hydrogen program.

\section{Approach}

We are planning to pursue a two-pronged approach to hydrogen safety training:

- Most researchers participating in the hydrogen program can benefit from basic training on hydrogen and pressure safety. This web-based training can be completed in $\sim 4$ hours.

- Pressure operators in charge of setting up experimental equipment require comprehensive education on all aspects of hydrogen operation, in addition to the web-based training on hydrogen fundamentals.

\section{Results}

We have developed a web-based class with basic safety information for hydrogen researchers available through the following provisional link,

https://www-training.1lnl.gov/training/hc/HS5094DOEW/index.html

A more intuitive, easy to remember link will be unveiled soon. Readers are invited to take the class and submit comments to the authors that may improve the learning experience and/or update the class information.

The class takes $\sim 4$ hours for completion, and includes six modules:

- Introduction (5 minutes): course description, navigation, study guides.

- Hydrogen properties (20 minutes): buoyancy, dispersion, ignition, flame and leak detection, ventilation, ignition sources, protective equipment.

- Pressure safety (60 minutes): pressurized systems (Figure 1), system components, 
stored energy considerations and calculations, basic design criteria, material properties, pressure ratings, safety factors, gas cylinder use and storage.

- Cryogenic safety (15 minutes): cryogenic fluid properties, thermal hazards, pressure hazards, expansion charts, asphyxiation, liquid air, safety measures.

- Emergency response (15 minutes): hydrogen posted signs, alarms, emergency crews, emergency instructions.

- Codes and standards (15 minutes): importance, organizations developing codes relevant to hydrogen, applicability, local and external resources.

Each module is followed by a quiz. After successful completion of all module quizzes (85\% passing grade) the student will receive class credit. If a module quiz is failed, the student has the opportunity to review the module and retake that quiz.

This is a self-paced course that may take several hours to complete. However, it is not necessary to complete the course at one time. This course will track progress, allowing students to leave the course and continue where they left off when they return.

Navigation through the class is simple: from any location the student can easily jump to different modules at any time by pressing the "menu" button above.

The pressure safety module is the longest and most demanding module of the course. To better assist the student in learning the information, this module provides practice questions as a preview of the module quiz. We recommend students to carefully go through these practice questions to be better prepared for the end of module quiz.

In addition to the web-based fundamentals class, we are also working on the development of a hands-on hydrogen safety class for pressure operators. This comprehensive training includes basic hydrogen safety, regulators, relief devices, leak detection, cryogenics, and fire safety, followed by hands-on assembly and test of a hydrogen pressure system and a final evaluation. Training can be conducted during a three-day session at LLNL or at remote institutions with appropriate facilities.

While work in this more comprehensive "hands-on" class is just starting, we have been able to prepare two working tables and instructional materials including segmented pressure components (regulators, valves, gauges; Figure 2). We anticipate FY11 completion and start of instruction.

\section{Conclusions and Future Directions}

- We are contributing to safe hydrogen operations by developing instructional materials for researchers and operators.

- Web-based class (now complete) addresses the need of laboratory researchers handling small amounts of hydrogen.

- Hands-on class (in process) will present in-depth information for technical personnel tasked with installing and testing hydrogen systems.

- Participation from the hydrogen community will improve the class through suggestions, bug reports, etc. 


\section{FY 2010 Publications/Presentations}

None.

Figure captions:

Figure 1. A screen image from the Pressure Safety module of the web-based "Hydrogen Safety Class for Researchers"

Figure 2. A working table and different pressure components cut to illustrate internal structure and operability. 


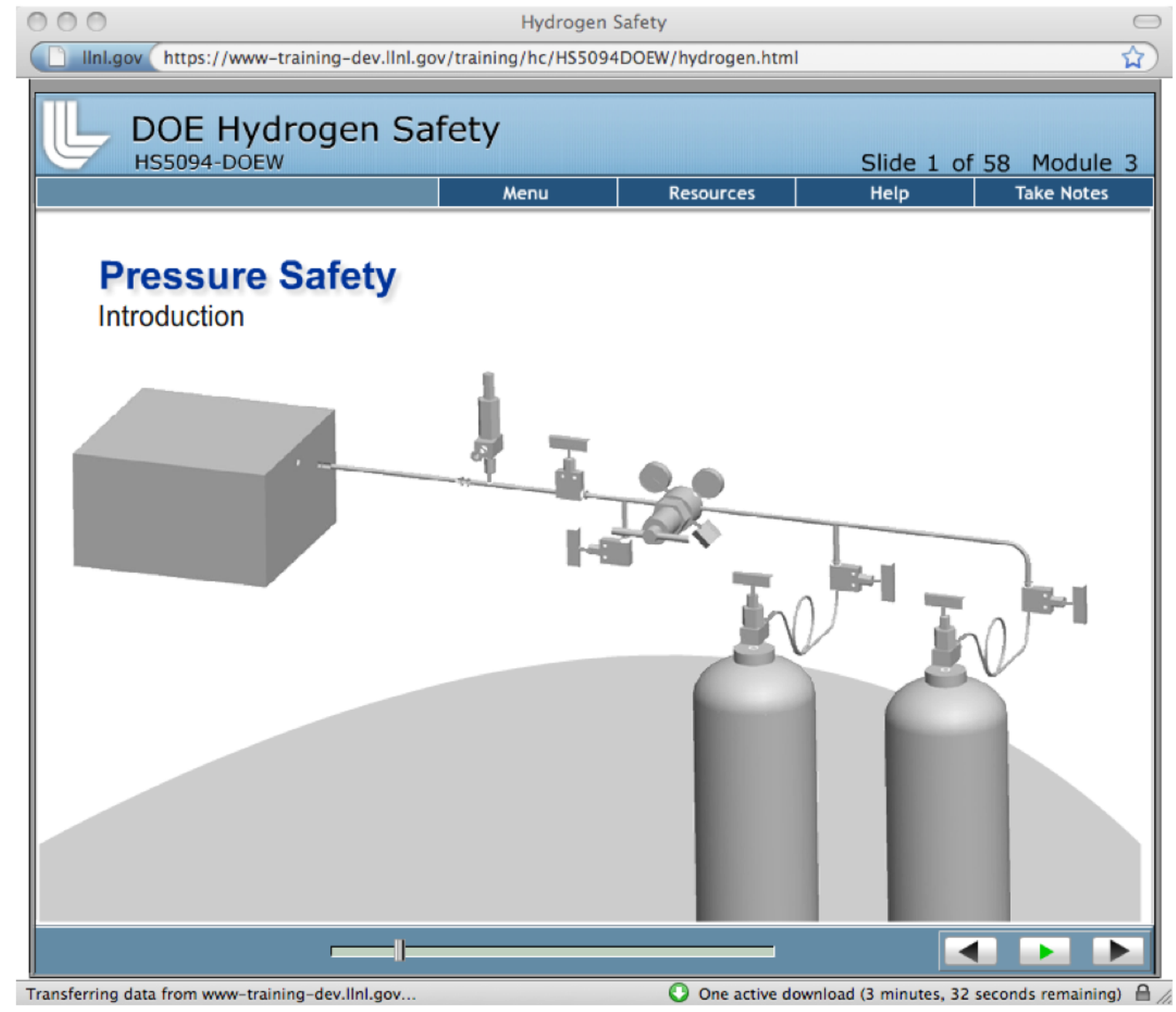

Figure 1 


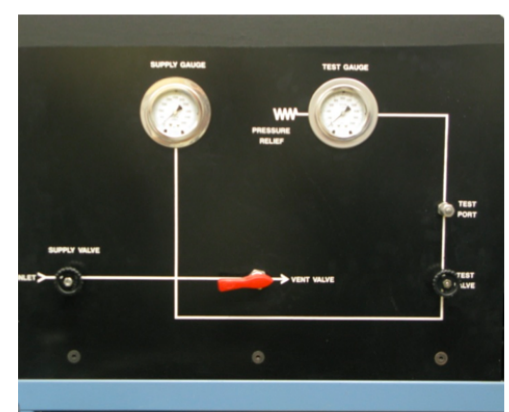

Working table

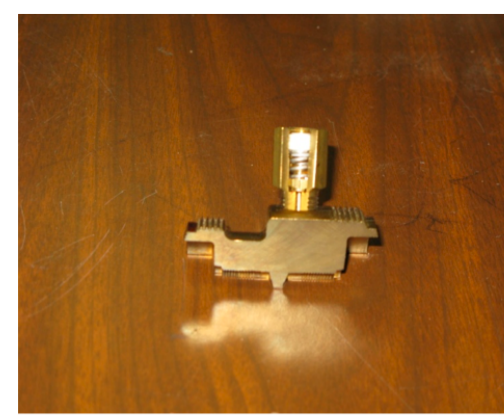

Relief device

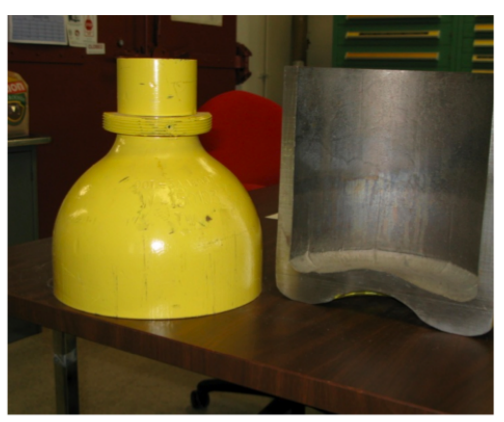

Pressure vessels

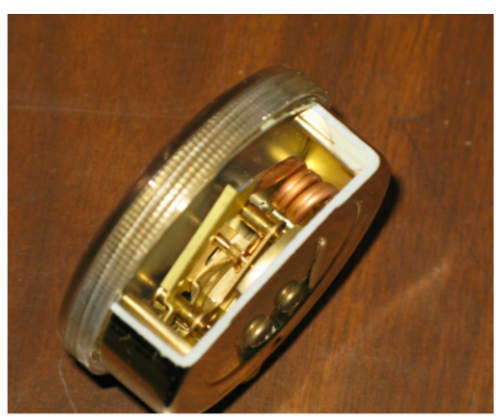

Pressure gauge

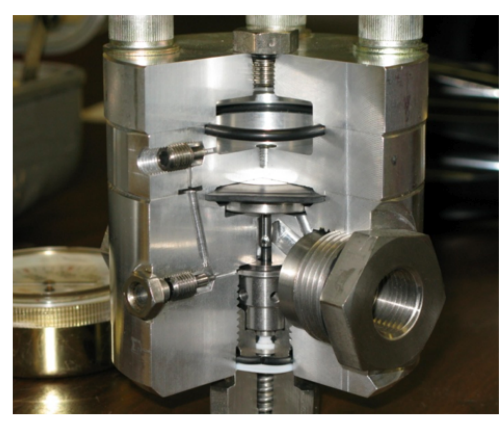

Regulator

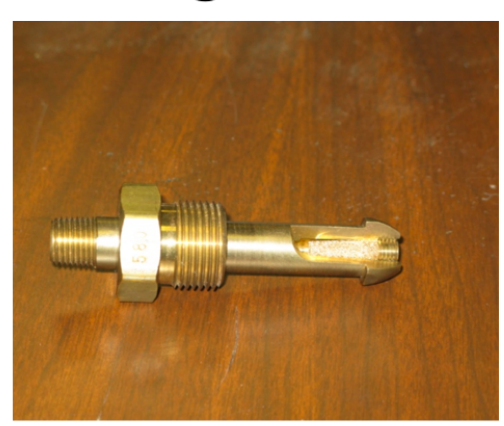

CGA fitting Figure 2. 